\title{
ORAL TISSUE DIAGNOSTIC SERVICES: A REVIEW OF THE LITERATURE
}

Tan B.H., Siar C.H. Oral Tissue Diagnostic Services: A Review of the Literature. Annal Dent Univ Malaya 1999; 6 . $27-30$.

\section{ABSTRACT}

Diagnosis by histopathology remains as one of the most important investigative methods used to establish a definitive diagnosis of a lesion or disease state. The provision of oral tissue diagnostic services is therefore an essential function of an Oral Pathology unit. A review of the English language literature disclosed that much of the documented information on the patterns of oral diagnostic services were from the United States, Canada and the United Kingdom. This paper provides an overview of such surveys carried out in these countries.

Keywords: Oral pathology, diagnostic services

\section{INTRODUCTION}

Acquaintance with patterns of utilisation of oral pathology diagnostic services is a necessity for extrapolating the growth and development of this field in future(1-12). The other main reasons include the need to instil greater awareness amongst dental and medical professionals of Oral Pathology as a dental speciality and also to emphasise the importance of histopathological confirmation of all excised tissues.

The three main purposes of establishing tissue diagnostic services are:

1. To make available such a facility to the local general dental or medical practitioners, hospital health care professionals and other health care providers.

2. As a means to obtain material for teaching purposes.

3. To act as a source of research material for the study of oral diseases in the local population.

The procurement of a biopsy is part of the oral health services. This procedure is carried out by all dental professionals. Previously, it was mostly performed by the dental specialists in particular oral surgeons. However nowadays, general dental practitioners also do biopsies.

\section{Literature review of surveys of oral tissue diagnostic services}

United States of America

Surveys of tissue diagnostic services first started in the 1950 's. The United States of America was amongst the earliest countries involved in this auditing programme. In 1960, Shafer et al.(1) compared various aspects of dental school biopsy services by means of a questionnaire. Questions were asked concerning the tissue diagnostic service's availability, administration, support, fees, number of specimens, utilization, number of malignancies and whether students were required to perform a biopsy before graduation.(1)

In 1971 Pullon and Miller(2) did a similar study and compared their findings with those conducted earlier by Shafer et al.(1) i.e. for the years 1953 and 1958. They found that there has been a modest increase in the

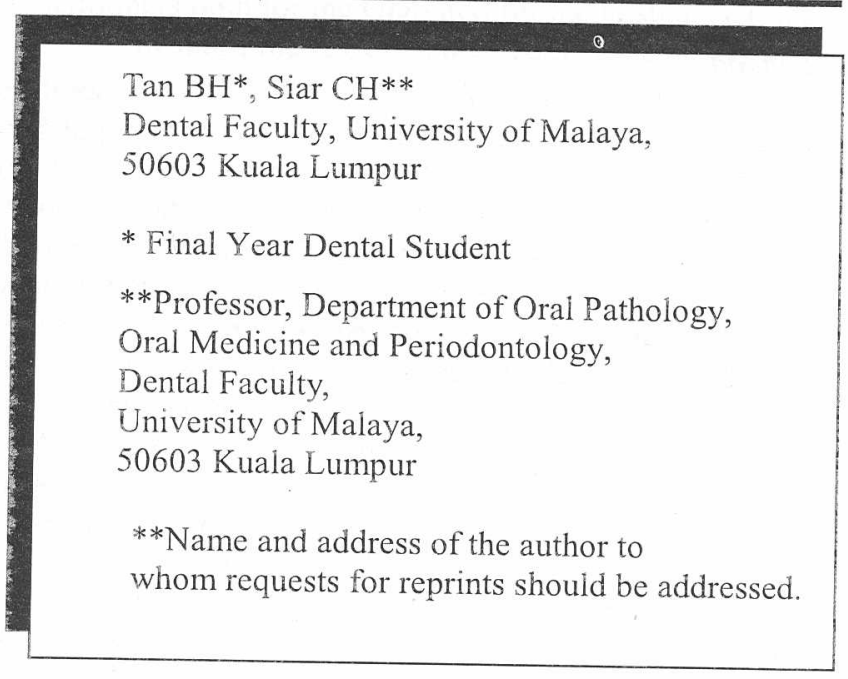

percentage of schools offering a tissue diagnostic service to outside practitioners, with the dental schools assuming at least partial control of almost all these services. The administrative responsibility for the tissue diagnostic service has been centred most often in the departments of pathology or oral pathology in the past 11 years(2). Support for the service continued to vary widely among the schools. In 1953, about half the schools charged a fee to outside practitioners; in 1969, all but one charged a fee ranging from US\$5 to US \$18.

Utilisation of dental school tissue diagnostic services has increased greatly with more than 45,000 specimens processed in 1969(2). The average number of specimens per laboratory increased $482 \%$ and $240 \%$ in 1969 as compared with 1953 and 1958 respectively $(1,2)$. The range of the number of biopsy specimens also increased with three schools each processing more than 3,475 specimens in 1969. The largest number of specimens processed by any school in 1953 was 690. The dental school tissue diagnostic services showed a remarkable increase in utilisation by outside practitioners in 1969; the ratio of numbers of specimens from the school to the number of specimens from outside practitioners was reversed compared with the 1953 figures. There was a significant increase in the number of malignant specimens processed in 1969 but a moderate decrease in the percentage of malignant specimens among the total number of specimens(2). This is seen not only in the increased numbers of biopsy accessions, which increased by $37 \%$ in 1990 compared with the last survey in 1985, but is also reflected in the diversity of services now offered by oral pathologists as well as in the utilization of the services by outside practitioners(3). Viewing the increasing use of diagnostic service by outside practitioners, the increased emphasis on teaching biopsy techniques in dental schools and emphasis on their value to the practitioner seem to have been most successful. It is deeply believed that the significant factor resulting in the increased utilization of dental school tissue diagnostic services by outside practitioners has been the increasing number of schools 
requiring each student to perform at least one biopsy before graduation. The number of schools with this requirement has been grown significantly(2).

\section{Canada}

Few surveys regarding the oral pathology biopsy services were conducted in Canada. These pursued recommendations made at the teaching conference in Oral Pathology. In 1982, delegates attending the Canadian Dental Association Oral Pathology Teaching Conference ${ }^{4}$ concluded that an active diagnostic oral pathology biopsy service is an integral component of an oral pathology department. Such a service is necessary to provide teaching material, to encourage students in the application of basic biological sciences in clinical practice and to maintain staff expertise. Conference participants also stated that students should be taught, or be made aware of, diagnostic laboratory and surgical pathology procedures and should be encouraged to participate actively in the diagnostic process. Similar concepts are embodied in the American Association for Dental Schools Curricular Guidelines for Pathology(5).

A survey by Priddy et al.(6) in 1984 was undertaken to investigate the various administrative, pedagogical, service aspects of oral pathology and availability of oral pathology services in Canadian dental schools. Their report covers the accessioning period 1977 to 1981 and reflects the administrative and teaching status of the various services as of July 1982. It documents the viability of oral pathology services in Canadian dental schools and the significant advances that have been made in the last five years(6).

The significance of an active oral pathology service in a dental school and its interfacing with the undergraduate curriculum comes at a time of greater emphasis on the biological principles underlying dentistry(6). During the next 20-25 years dentists will assume a greater degree of responsibility for the overall health of their patients(8-9). If the practitioner is to have a firm understanding of the patho-biology of oral, paraoral and systemic disease, then the foundation for this knowledge and its application must be set in the dental curriculum. In this regard, didactic and clinical oral pathology courses are vital to the dental education process.

The Canadian Academy of Oral Pathology conducted a survey of its active members to obtain information on their demographics, professional activities and university affiliations, update data regarding Canadian oral pathology diagnostic services, assess the specialty's manpower needs and Canada's present and future oral pathology needs(10). Data were also collected on Canadian oral pathology diagnostic biopsy services. This survey(10) revealed actual conditions of oral pathology diagnostic biopsy service pertinent to administration or staffing, funding and source of accessions. Collated from the Priddy's(6) 1984 report, the basic concept of biopsy services has changed very little. Most laboratories are based at dental schools. Their funding has not change significantly, with only a modest increase in the average fee. However, there has been a continuous growth in the use of these services in Canada, particularly by dentists in general practice. The average annual number of accessions from eight services was 845 between 1977 and 1981, while the average annual number from five schools reached 1,930 between 1987 and 1989(10). The rate of growth was down, however. From 1977 to 1981, accessions increased 15 to 16 per cent annually, but by only six to eight per cent per year, approximately, from 1987 to 1989. Priddy's(6) figures are not directly comparable with those obtained by Daley et al.'s(10) survey, since more biopsy services were included in his survey.

In another related work in 1988, the relative incidence of odontogenic tumours and oral and jaw cyst in a Canadian population was carried out(11). The results give important data on assessing geographic differences in the incidence of lesions and to allow clinicians to make realistic judgments in counseling patients before biopsy about the probability of diagnosis and risks associated with non-specific clinical or radiographic lesions(11). This implicated that the establishment of oral pathology diagnostic services boost the dental professionals knowledge(12).

\section{United Kingdom}

In 1997, as part of an ongoing medical audit programme in the Oral Pathology Unit at the Birmingham Dental Hospital and School, Williams et al.(13) conducted a survey to assess the use by general dental practitioners of an oral pathology diagnostic service over a 20 -year period. They carried out a retrospective analysis of the number of cases received for histological examination in 1975, 1984 and 1994. As far as these authors are aware, there has been no previous study of the use of such kind of service by general dental practitioners(13). In their study(13), 1101,2395 and 3366 specimens were accessed respectively for the three years studied. The number and proportion of specimens received, number and proportion that were hard or soft tissue specimens and the information on the request form were recorded. A comparison was made between the provisional clinical and histological diagnoses. They found that the number of specimens accessed increased approximately 3 -fold, but in reality the number of specimens accessed from general dental practitioners increased 5 -fold. The variety of histological categories increased by over $50 \%$, most being soft tissue specimens. The number of correct provisional diagnoses increased steadily but the percentage with inappropriate provisional diagnoses remained the same. Information on request forms steadily improved. Their survey showed that the number of specimens received from general dental practitioners increased steadily over the 20 -year period, which reflects increasing demand from this particular group of dental professionals for diagnostic histological services, therefore confirming the need to provide this specialist service. Further, the range of diagnostic entities has widened. These trends indicate that general dental practitioners are treating a wider range of clinical problems than previously and presumably reflects the better training that is now available. However, while hard tissue lesions appear to present relatively little problem in clinical diagnosis, some oral mucosal lesions still present 
difficulties. In view of the continuing dental education and an increased knowledge of the differential diagnosis of mucosal lesions these diagnostic difficulties should continue to decline(13).

Besides the above mentioned studies conducted on tissue diagnostic services, there were also several related investigations notably those concerning oral surgery services. Because trends and demands in oral surgery services would directly or indirectly influence tissue diagnostic services it is felt that it would be pertinent to discuss this here. In 1994 Thomas et al.(14), in Cardiff carried out a survey on the provision of oral surgery services in England and Wales from 1984 to 1991. A previous National Audit demonstrated a substantial increase in demand for oral surgical services in England and Wales in the period 1979-1984. Despite a $32 \%$ increase in patient throughout and a $52 \%$ increase in minor oral surgery carried out within the General Dental Service during that period, a $66 \%$ increase in the numbers of people waiting for in-patient surgery also occurred. These findings suggested that demand for these services was exceedingly high. This study, however, only investigated changes up to the end of 1984 and a second audit is now needed; particularly as the rate of change reported in the previous study was rapid in many areas and current activity is the basis upon which contracts for the purchase of care are being drawn up and policy concerning specialist oral surgery practice is being developed(15).

Data from the Department of Health and the Dental Practice Board demonstrate substantial increases in the volume of oral surgery performed in England and Wales both in the General Dental and Hospital Services during the period 1984-1991 (Dental Estimates Board/Dental practice Board Annual Report)(16). In the General Dental Service(GDS), although the number of routine extractions decreased by $10 \%$, the number of surgical procedures increased by $20 \%$, with a substantial increase $(33 \%)$ in the number of third molar extractions in the period 1988-1991. There have been no decreases in the annual rate of extractions of permanent and deciduous teeth in the GDS since 1987. In at least one Regional Health Authority, there was a five-fold increase in the number of oral surgery patients aged 0-9 years treated in the hospital service (1982-1991). Overall, although this study takes no account of extractions carried out in the Community Service, these findings suggest that the numbers of deciduous extractions may have actually risen in some areas, particularly after 1987. In the Hospital Service there was a $55 \%$ increase in numbers of day-cases, from 30,090 (1984) to 46,499 (1990); a $10 \%$ increase in numbers of in-patients and a $13 \%$ decrease in numbers of people waiting for in-patient surgery. These changes were in the same direction as those in plastic and ENT surgery; though plastic surgery achieved a greater utilization of day-care services. Through their study Thomas et al.(14), demonstrated how the practice of oral surgery is continuing to evolve in the United Kingdom. Rationalisation in the provision of oral surgery services is likely to occur in the next decade; with increasing numbers of patients requiring minor oral surgery being treated in the GDS. Such changes will have important implications for manpower planning and education. These include increasing emphasis on oral surgery training in the dental undergraduate course and in vocational training and the development of training programmes for specialist practitioners both for the GDS and for the hospital service.

In short, the review indicated that the provision of oral surgery increased during 1984-1991, and suggests that more will be carried out in general practice in the future.

In a simpler way, the provision of oral pathology diagnostic services has a significant effect on the overall performance of dental services. This is not helped by the limited research on the utilisation of such kinds of service. Over the years, considerable changes have been made not only to improve and advance our system of education, but also in the provision of health needs including dental health services. In order to determine whether such changes affect the biopsy services or the use of laboratory services, auditing programmes should be devised to monitor these changes more effectively.

For all years, periapical scar tissue was consistently incorrect diagnosed clinically because of its rare occurrence. Hence the dental practitioners have difficulty diagnosing them clinically. The dental follicle was one of the consistently incorrect diagnosed lesions despite of its typical site of occurrence. Chronic hyperplastic candidiasis as one of the consistently incorrectly diagnosed lesions is relatively uncommon condition and only a small number of cases were submitted.

\section{Comment}

In modern day dentistry, the dentists will have to assume a greater degree of responsibility for the overall oral health of their patients. The practitioners should have an in-depth knowledge and understanding of the pathobiology of oral, paraoral and systemic diseases. To achieve this aim, it is a must to set a foundation for this knowledge and its application in clinical time. These could be set in the undergraduate dental curriculum. In this regard, didactic and clinical oral pathology courses are vital to the dental education process. This change of responsibility will have important implication for manpower planning besides the aspect of education. More oral pathologists would be needed in educational activities. They would probably devote bigger portion of their time to teaching.

It is obvious right from the start that oral pathology diagnostic service is important both to dental students and practitioners. The service acts as a source of research material for the study of oral diseases and submission of surgical material for undergraduate and graduate teaching purposes. Furthermore, it provides diagnostic aid to the practitioners to reach a definitive diagnoses. With its significance, continuing efforts must be made to ensure that the service and teaching role remain in step and are responsive to the profession as it moves towards the next century.

\section{ACKNOWLEDGEMENTS}

This paper is part of an elective student project presented at the First Dental Student Scientific Conference held here in Kuala Lumpur on 19-20 November 1999. The authors gratefully acknowleged the assistance of all the staff of the Department of Oral Pathology, Oral Medicine \& 
Periodontology; and the support and subsidy approved by the Dean, Faculty of Dentistry to fund this study.

\section{REFERENCES}

1. Shafer WG. Comparison of surveys of dental school biopsy services. J Dent Educ 1960; 24: 298-303.

2. Pullon PA, Miller AS. Survey of tissue diagnostic services in US dental schools. J Am Dent Assoc 1971; 83: 1097-100

3. Miller AS, Cleveland DB. Survey of tissue diagnostic services in U.S. dental schools - 1990. Oral Surg Oral Med Oral Pathol 1992;73:717-19.

4. Canadian Dental Association Teaching Conference: The Teaching of Oral Pathology in the Undergraduate Dental Curriculum. April 16, 1982.

5. American Association for Dental Schools Curricular Guidelines for Pathology. J Dent Educ 1980; 44: 61115.

6. Priddy RW. A survey of Oral Pathology biopsy services in Canadian dental schools. J Can Dent Assoc 1984; 50: 829-32.

7. De Paola DP. Application of basic and medical sciences in the dental curriculum. J Dent Educ 1981; 45: 685-91.

8. Morris AL. Health sciences education in the twentyfirst century: Who is to do what work in dentistry? J Dent Educ 1976; 40: 655-61.

9. Cohen WD. Dental education of the future. J Dent Educ 1981; 45: 713-18.
10. Daley TD, Wysocki GP, Main JHP, Ahing S, Lovas JGL. Oral Pathology in Canada: a survey. J Can Dent Assoc 1992; 58: 647-52.

11. Daley TD, Wysocki GP, Pringle GA. Relative incidence of odontogenic tumors and oral and jaw cysts in a Canadian population. Oral Surg Oral Med Oral Pathol 1994 : 276-80.

12. Kaugars GE, Burns JC, Gunsolley JC. Epithelial dysplasia of the oral cavity and lips. Cancer 1988; 62: 2166-70.

13. Williams HK, Hey AA, Browne RM. The use by general dental practitioners of an oral pathology diagnostic service over a 20 year period: The Birmingham Dental Hospital experience. Br Dent J 1997; 182: 424-9.

14. Thomas DW, Smith AT, Walker R, Shepherd JP. The provision of oral and maxillofacial surgery services in England and Wales 1984-1991. Br Dent J 1994; 176 215-29.

15. Shepherd JP, Jones GM. Trends in Oral Surgery practice. Br Dent J 1987; 163: 237-39.

16. Dental Estimates Board/Dental Practice Board Annual Reports:1984-90.

17. Regezi JA, Sciubba J. Oral Pathology ClinicalPathologic Correlations. $2^{\text {nd }}$ edition. Chapter 2:Ulcerative Conditions. WB Saunders Company, Philadelphia, 1993: 78-9. 